\title{
Runway behavior of the gray rat snake with food and water reinforcement'
}

F. T. CRAWFORD AND CHARLES W. BARTLETT

FLORIDA STATE UNIVERSITY
Two groups of gray rat snakes were given training in an enclosed alleyway. Both groups were maintained on a seven day food and water deprivation schedule. Ss of the experimental group were run to food and water reinforcement. Control Ss were run in the same manner except that there was no reinforcement in the goal box. All $S$ s received one trial every seven days unless they were moulting. Measures of latency and running time produced diverging curves for the experimental and control groups, due principally to the increase in both measures for the latter group.

Two studies have been most frequently cited as laboratory investigations of behavioral modification in snakes. One (Kellogg \& Pomeroy, 1936) concerned the ability of water snakes to escape from a relatively cold water temperature in a water $\mathrm{T}$-maze into a goal box having a higher water and air temperature. The results showed that individual snakes varied greatly in their performance, assumed to be due in part to ecdysis, but that the progress of the entire group was characterized by a drop in time and errors.

The second study (Wolfle \& Brown, 1940) employed a dry multiple $\mathrm{T}$-maze at a high temperature. The snakes were supposed to escape from the maze into a shaded pan of water. The snakes failed to show evidence of learning, perhaps due to the extremely high temperature used $\left(48^{\circ}-55^{\circ} \mathrm{C}\right)$, although this was not the conclusion reached by the investigators. Wolfle and Brown further attempted to use electric shock as a noxious stimulus, but again failed to demonstrate learning.

The present investigation attempted to demonstrate runway acquisition to positive reinforcement in contrast to the above experiments studying learning as a function of escape conditioning. Preliminary studies from this laboratory indicated that gray rat snakes would drink water readily following deprivation, although attempts to train them to run down a runway to water reinforcement failed when they were tested in an apparatus having a transparent lid. These snakes were feeding regularly under laboratory conditions so it was decided to run them to food and water reinforcement in a runway having an opaque cover.

Method

Ss of the experiment were eight gray rat snakes, Elaphe obsoleta spiloides, measuring $91.4-152.4 \mathrm{~cm}$ at the beginning of the experiment. Ss were divided into two groups, a control group (C) and an experimental group (E), of four Ss. A S in the C group was discarded prior to actual training because of irregular eating habits. This $\mathrm{S}$ was the smallest snake and its size, in addition to the fact that it had been more recently captured, may have contributed to its lower food requirements. All the remaining Ss were over 122.0 $\mathrm{cm}$ in length. Ss were maintained on one or more small chickens per week and were observed to eat regularly and readily. They were housed in individual aquariums under conditions of controlled humidity $(40 \%)$ and temperature $\left(25.5^{\circ} \mathrm{C}\right)$.

Ss were run in a $182.9 \mathrm{~cm}$ wooden alleyway having a start box and goal box each $30.5 \mathrm{~cm}$ in length. The internal height and width of the alleyway were 15.2 and $14.0 \mathrm{~cm}$ respectively. The start box and runway were each covered by separate hinged wooden lids. The goal box was covered by a hinged transparent lid of plastic. Each of the partitions separating the runway from the goal box and start box had a $4.4 \mathrm{~cm}$ diameter hole centered in the partition. On the runway side of each partition a photo cell and light source were mounted so that the passage of the $S$ through the hole in the partition operated relays controlling two chronometers. The chronometers were wired to give separate goal box latency and runway running time. The exterior of the apparatus was painted flat black, but the interior was unfinished.

Ss were placed on a seven day food and water deprivation schedule four weeks prior to the beginning of the experiment. Ss were then given one trial every seven days unless they were in some state of ecdysis. Under such conditions the trial was postponed until the next trial would normally occur. Ss in the E group were run to food and water reinforcement. A young chicken and a small bowl of water were placed at the end of the goal box on each trial. The chicken was secured by a silk cord made into a slip knot around the chicken's leg. The cord passed through a small hole in the wall of the goal box. After the snake had tripped the second photocell relay the chicken was released by pulling the cord. If $\mathrm{S}$ did not leave the start box within $30 \mathrm{~min}$. a latency and running time of $30 \mathrm{~min}$. was arbitrarily assigned. This procedure was necessary on two occasions: on the first trial of one $E \mathrm{~S}$; and on the last trial of one C S. Each S was allowed up to $60 \mathrm{~min}$. following the release of the chicken to eat and drink. Feeding usually took place immediately but some chickens were larger and more aggressive and thus delayed feeding. There were two instances in which a $S$ did not eat in the apparatus. These occurred on the first trial of two Ss. 
Ss in the $\mathrm{C}$ group were begun four weeks after the $\mathrm{E}$ group when it became apparent that the E Ss demonstrated an initial decrease in latency and running time followed by only a relatively lower although variable response level. Ss in the $\mathrm{C}$ group were rur in the same manner as the $E$ group except that food and water were not located in the goal box. Following each trial the $\mathrm{C}$ group Ss were given access to food and water in the home tank for an hour. Results and Discussion

The E Ss were run over a 14 week period, and the C Ss over a 10 week period. The experiment was terminated at this time because of an inability to obtain chickens from hatcheries in Northern Florida and Southern Georgia during the late summer, a situation which had not been anticipated. As indicated above Ss were not run when moulting and at the end of the experiment 12 trials had been completed by two $\mathrm{E}$ Ss, and 11 trials by the remaining $2 \mathrm{E} \mathrm{Ss}$. All Ss in the $\mathrm{C}$ group had completed eight trials. For convenience in presenting the data the two Ss in the $\mathrm{E}$ group receiving only 11 trials were assigned the same scores on the 12th trial as they obtained on the 11th. The data for the two groups were then "Vincentized" by determing the running means of every seven and three trials for the $E$ and $C$ groups, respectively. Thus trials $1-7,2-8,3-9, \ldots, 6-12$ for the $\mathrm{E}$ group, and trials $1-3,2-4,3-5, \ldots, 6-8$ for the $C$ group appear for latency and running time measures in Fig. 1. It may be seen from Fig. 1 that the $\log$ mean latencies and munning time for the $\mathrm{E}$ group are initially low, and remain so during the course of the experiment. The Ss of the $\mathrm{C}$ group, however, show a continuing increase in both latency and running time. The response time measures, i.e., the sum of the latency and running time scores, are not plotted because of the similarity of the $\mathrm{E}$ and $\mathrm{C}$ group latency and running time curves. The initial difference between the $\mathrm{E}$ and $\mathrm{C}$ groups in running time are due to the first two trials. Since the $E$ group Ss initiated their trials in the apparatus when

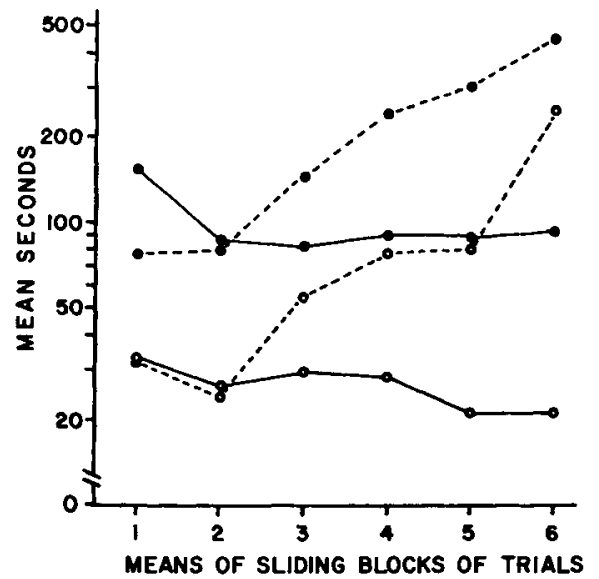

Fig. 1. Log mean latencies (open circles) and running times (solid circles) for experimental (solid lines) and control (broken línes) groups.

the odor and other stimuli from the presence of snakes and chickens, were not so pronounced, this initial difference is assumed to be a procedural artifact. Nevertheless the lack of "acquisition" in the $\mathrm{E}$ group and the essential "extinction" of the C group is perhaps the most interesting outcome of the experiment. Such behavior would not necessarily be considered unusual in a rat study, but snakes have a well-earned reputation for being refractory Ss only intermittantly responsive to appetitional deprivation. The cliche concerning the distinction between performance and learning being a function of motivation appears to apply to the snake as well as to other organisms.

\section{References}

Kellogg, W. N., \& Pomeroy, W. B. Maze learning in water snakes. J. comp. Psychol., 1936, 3, 275-298.

Wolfle, D. L., \& Brown, C. S. A learning experiment with snakes. Copeia, 1940, 134.

\section{Note}

1. This research was partially supported by a grant from the Florida State University Research Council. 